\title{
Colitis isquémica estercorácea
}

\author{
Sterraceous isquemic colitis
}

Ainhoa Andrés Imaz ${ }^{1}$, Asier Martín López ${ }^{1}$, Araceli Rodríguez González y José María Enríquez Navascués ${ }^{1}$

Varón de 79 años polimedicado y con estreñimiento crónico severo (ECS). Consulta por dolor abdominal, encontrándose hemodinámicamente inestable, distendido con irritación peritoneal generalizada, acidótico y con falla renal. Mediante tomografía computarizada se visualiza fecaloma en rectosigma y engrosamiento e hipocaptación mural de colon descendente, compatible con colitis estercorácea (CE) (Figura 1). Se decide laparotomía urgente con hallazgo de colitis isquémica estercorácea (CIE) de colon izquierdo con marcada necrosis (Figura 2). Se realiza hemicolectomía izquierda con evolución favorable.

La CE es una infrecuente complicación del ECS

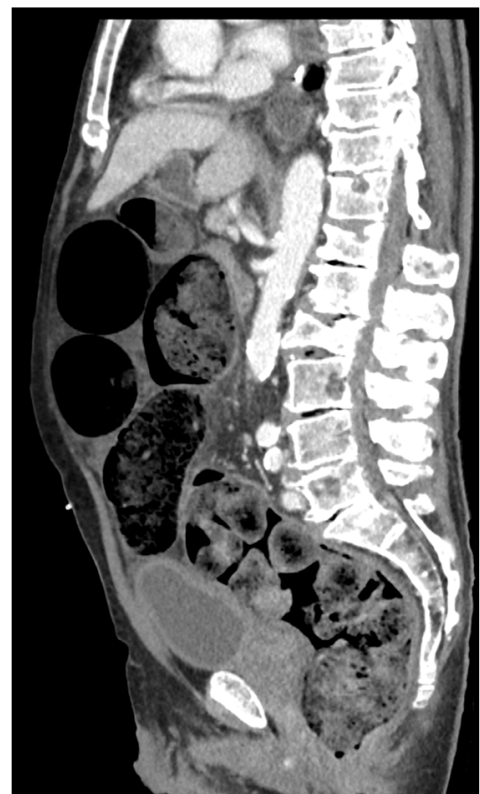

Figura 1. TC preoperatorio (corte sagital). con alta morbimortalidad en ausencia de manejo precoz, siendo importante sospecharla. Afecta a la población anciana, encamada o polimedicada. La formación del fecaloma condiciona una dilatación colónica retrógrada, causando una colitis por hipoperfusión que puede progresar hacia la necrosis y la perforación. Afecta al sigma/rectosigma en $90 \%$ de los casos ${ }^{1}$.

La CIE es una complicación excepcional, pero grave (mortalidad 33\%). Requiere tratamiento inmediato, idealmente mediante desimpactación fecal manual o endoscópica, dejando la cirugía para casos de peritonitis difusa ${ }^{2}$.

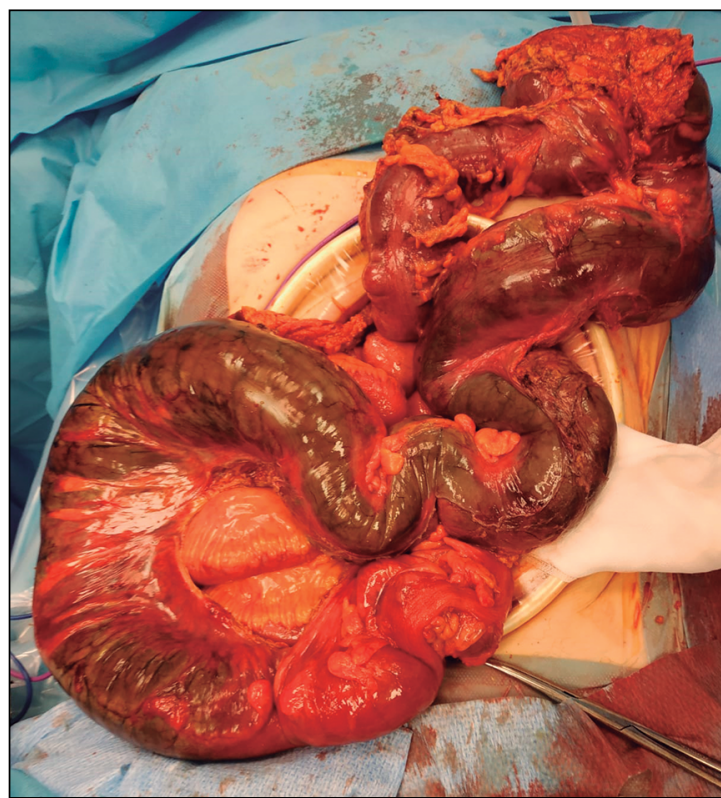

Figura 2. Imagen intraoperatoria.
Hospital Universitario Donostia. Donostia, Gipuzkoa, España.

Recibido el 5 de marzo de 2020 y aceptado para publicación el 9 de marzo de 2020

Correspondencia a:

Dra. Ainhoa Andrés Imaz ainhoa.andresimaz@

osakidetza.eus 


\section{Responsabilidades éticas}

Protección de personas y animales. Los autores declaran que para esta investigación no se han realizado experimentos en seres humanos ni en animales.
Confidencialidad de los datos. Los autores declaran que en este artículo no aparecen datos de pacientes.

Conflictos de interés: no hay.

\section{Bibliografía}

1. Wu CH, Wang LJ, Wong $\mathrm{YCh}$, Huang $\mathrm{ChCh}$, Chen $\mathrm{ChCh}$,

Wang ChJ, et al. Necrotic stercoral colitis:
Importance of computed tomography findings. World J Gastroenterol. 2011;17:379-84. doi: 10.3748/wjg.v17. i3.379.

2. Naseer M, Gandhi J, Chams N,
Kulairi Z. Stercoral colitis complicated with ischemic colitis: a double-edge sword. BMC Gastroenterology2017;17:129. doi:10.1186/s12876-017-0686-6. 